\title{
Atividade antifúngica de óleos essenciais in natura e ozonizados sobre o agente etiológico da esporotricose
}

A esporotricose é uma micose causada por espécies de Sporothrix schenckii. O tratamento desta doença é realizado utilizando antifúngicos convencionais. A emergência de cepas resistentes tem ocasionado tratamentos alternativos, como os medicamentos naturais ou emprego do gás ozônio. Objetivou-se nesta pesquisa avaliar a atividade antifúngica de óleos essencias in natura e ozonizados frente a Sporothrix schenckii. Foram empregados óleos essenciais in natura e ozonizados de Cinnamomum cassia, Syzygium aromaticum, Cymbopogon winterianus, Eucalyptus globulus, Eucalyptus staigeriana e Mentha piperita, avaliados quanto a atividade antifúngica frente a linhagem padrão de Sprothrix schenckii ATCC 16345. Os óleos foram ozonizados em equipamento corona. Utilizou-se a técnica de microdiluição para avaliar a concentração inibitória mínima (CIM) e a concentração fungicida mínima (CFM). Foi determinada a cinética fungicida dos óleos essenciais. Os dados obtidos foram avaliados pelos Teste de Mann-Whitney e pelo este de Kruskal-Wallis. Os óleos essenciais in natura e ozonizados de canela, cravo, citronela, eucalipto e menta apresentaram atividade antifúngica frente a Sporothrix schenckii. O óleo de cravo ozonizado foi mais eficaz na redução da carga fúngica, sendo necessários 20 minutos para eliminar totalmente as estruturas fúngicas, evidenciando a possibilidade do uso na terapêutica antifúngica de S. schenckii.

Palavras-chave: Sporothrix schenckii; Ozônio; Plantas medicinais.

\section{Antifungal activity of essential oils in natura and ozonized on the etiological agent of sporotrichosis}

\begin{abstract}
Sporotrichosis is a ringworm caused by species of Sporothrix schenckii. The treatment of this disease is carried out using conventional antifungals. The emergence of resistant strains has led to alternative treatments, such as natural medicines or the use of ozone gas. The aim of this research was to evaluate the antifungal activity of fresh and ozonated essential oils against Sporothrix schenckii. Fresh and ozonated essential oils of Cinnamomum cassia, Syzygium aromaticum, Cymbopogon winterianus, Eucalyptus globulus, Eucalyptus staigeriana and Mentha piperita were used, evaluated for antifungal activity against the standard strain of Sprothrix schenckii ATCC 16345. The oils were ozonated in corona equipment. The microdilution technique was used to assess the minimum inhibitory concentration (MIC) and the minimum fungicidal concentration (MFC). The fungicidal kinetics of essential oils were determined. The data obtained were evaluated by the Mann-Whitney test and the Kruskal-Wallis test. The natural and ozonated essential oils of cinnamon, cloves, citronella, eucalyptus and mint showed antifungal activity against Sporothrix schenckii. Ozonized clove oil was more effective in reducing the fungal load, requiring 20 minutes to completely eliminate the fungal structures. Evidencing the possibility of use in S. schenckii antifungal therapy.
\end{abstract}

Keywords: Sporothrix schenckii; Ozone; Medicinal plants.

Topic: Epidemiologia e Saúde Ambiental

Reviewed anonymously in the process of blind peer
Received: 03/03/2021

Approved: 21/03/2021
Joelma Évelin Pereira Kume (it)

Universidade Brasil, Brasil

http://lattes.cnpq.br/2942478755661738

http://orcid.org/0000-0003-3486-7633

joelma.evelin@gmail.com

Roberto Andreani Junior (DD

Universidade Brasil, Brasil

http://lattes.cnpq.br/5863157086821275

http://orcid.org/0000-0002-0290-3356

robertoandreani@uol.com.br

Gisele Herbst Vazquez (iD)

Universidade Brasil, Brasil

http://lattes.cnpq.br/3050276760782685

http://orcid.org/0000-0002-0957-329X

gisele.vazquez@universidadebrasil.edu.br
Dora Inés Kozusny-Andreani (D)

Universidade Camilo Castelo Branco, Brasil

http://lattes.cnpq.br/1260217332585007

http://orcid.org/0000-0001-8518-0984

doraines@terra.com.br
Referencing this:

KUME, J. É. P.; ANDREANI JUNIOR, R.; VAZQUEZ, G. H.; KOZUSNYANDREANI, D. I.. Atividade antifúngica de óleos essenciais in natura e ozonizados sobre o agente etiológico da esporotricose. Revista Ibero Americana de Ciências Ambientais, v.12, n.3, p.126-135, 2021. DOI: http://doi.org/10.6008/CBPC2179-6858.2021.003.0012 


\section{INTRODUÇÃO}

A esporotricose é uma micose causada por espécies de Sporothrix schenckii, que compreende um complexo de várias espécies de fungos encontrados em solos, plantas, vegetais em decomposição e outros ambientes externos (BONIFAZ et al., 2017). Humanos e animais podem adquirir a doença por meio da inoculação traumática do fungo no tecido subcutâneo. A doença também pode ser adquirida de animais que atuam como vetores indiretos ou passivos (BARROS et al., 2011).

O maior número de infecções por S. schenckii ocorre no outono e inverno, quando nos países endêmicos a umidade relativa do ar é alta, pois se sugere que o clima, a temperatura atmosférica e a umidade relativa do ar influenciem no crescimento do fungo no seu estado saprofítico (SONG et al., 2013).

Apesar da importância da esporotricose, atualmente considerada uma doença emergente em vários países, os fatores que impulsionam sua crescente importância médica ainda são desconhecidos. Existem poucos estudos abordando a influência do meio ambiente na virulência desses patógenos. No entanto, existem evidências de que as condições adversas em seus habitats naturais podem desencadear a expressão de diferentes fatores de virulência que conferem vantagens de sobrevivência tanto em hospedeiros animais quanto no meio ambiente (RODRIGUES et al., 2013; TÉLLEZ et al., 2014).

O tratamento de escolha para a maioria dos casos de esporotricose é o antifúngico anfotericina B e subsequente itraconazol para terapia de manutenção (BONIFAZ et al., 2017).

No entanto, a maioria dos antifúngicos convencionais tem muitos problemas em termos de toxicidade, interações medicamentosas, falta de eficácia fungicida, custo do tratamento e a emergência de cepas resistentes. Portanto, a busca de medicamentos naturais obtidos de plantas com virtudes terapêuticas, impulsiona uma intensa demanda por novas moléculas mais eficazes e menos tóxicas (SIHAM et al., 2020).

Os medicamentos fitoterápicos são conhecidos como uma fonte significativa para a descoberta de novas moléculas farmacêuticas, as quais poderiam ser usadas para tratar doenças graves. Muitas espécies de plantas têm atividades farmacológicas atribuíveis aos seus fitoconstituintes, tais como glicosídeos, saponinas, flavonóides, esteróides, taninos, alcalóides, terpenos, entre outros (BATIHA et al., 2020).

Os fitoquímicos são considerados ambientalmente seguros, pois são biodegradáveis e têm pouca ou nenhuma toxicidade. Os óleos essenciais são hidrofóbicos e voláteis, extraídos de diferentes partes das plantas aromáticas conhecidos por possuírem atividades fungicidas, bactericidas, inseticidas, entre outras (KUMAR et al., 2014; SIDDIQUI et al., 2017).

A promissora atividade antimicrobiana dos óleos essenciais levou os pesquisadores a usá-los em combinação com substâncias antimicrobianas para reduzir a toxicidade da droga, efeitos colaterais e resistência a agentes únicos (TULLIO et al., 2019).

A ozonioterapia vem se destacando como uma opção para o tratamento para diferentes enfermidades, pois apresentam vantagens como baixo custo, a baixa invasividade, a ação antimicrobiana, fácil aplicação e a ausência de efeitos colaterais, intolerância ou contraindicações quando utilizada em doses terapêuticas (ZANARDI et al., 2016). 
Assim, a busca por um amplo espectro de agentes antimicrobianos que possam evitar a resistência e ao mesmo tempo que proporcionem efeitos colaterais razoáveis, fez com que os óleos ozonizados experimentassem um aumento no interesse científico e nas aplicações clínicas (ZANARDI et al., 2008; ALMEIDA et al., 2012; UGAZIO et al., 2020).

Neste contexto, objetivou esta pesquisa avaliar a atividade antifúngica de óleos essencias in natura e ozonizados frente a Sporothrix schenckii, agente etiológico da esporotricose.

\section{MATERIAIS E MÉTODOS}

\section{Linhagem e meios de cultivo}

Para avaliar a atividade antimicrobiana de óleos essenciais, foi utilizada a linhagem padrão de Sporothrix schenckii ATCC 16345 (American Type Culture Collection).

A linhagem foi reativada em meio de cultura agarizado Sabouraud Dextrose (ASD) e caldo Sabouraud Dextrose (CSD), adquiridos da Kasvi ${ }^{\circledR}$ e preparados de acordo com as instruções do fabricante. Os meios foram solubilizados com água destilada e esterilizados em autoclave, a $121^{\circ} \mathrm{C}$ por 15 minutos.

A linhagem de S. schenckii foi isolada em placas de Petri contendo meio de cultura estéril (ASD) e incubadas em temperatura de $28^{\circ} \mathrm{C}$, por um período 5 a 7 dias.

\section{Óleos essenciais}

Foram utilizados seis óleos essenciais sendo eles, Cinnamomum cassia (L.) Presl (Canela-da-china), Syzygium aromaticum (L.) Merrill. \& L. M. Perry (Folhas de cravo-da-índia), Cymbopogon winterianus Jowitt (Capim-citronela), Mentha piperita L (Menta) e duas espécies de eucalipto (Eucalyptus globulus L. e Eucalyptus staigeriana F. Muell. ex F. M. Bailey). Todos foram obtidos da indústria nacional Ferquímica ${ }^{\circledR}$, localizada em Vargem grande Paulista, SP, Brasil), sendo seus parâmetros físico-químicos como aparência, coloração, pureza, odor, densidade $\left(20^{\circ} \mathrm{C}\right)$ e índice de refração $\left(20^{\circ} \mathrm{C}\right)$, descritos pelo fornecedor, que produz e comercializa óleos essenciais em escala industrial.

\section{Ozonização dos óleos essenciais}

Para ozonizar os óleos essenciais, o gás ozônio $\left(\mathrm{O}_{3}\right)$ foi produzido por meio de um gerador corona (Ozon \& Life) e o oxigênio puro foi suprido via cilindro de oxigênio. O ozônio produzido de forma constante pelo equipamento foi conduzido por um tubo de silicone para o difusor. Os óleos foram expostos ao ozônio de forma direta por meio do difusor por 30 minutos, em temperatura controlada de $25^{\circ} \mathrm{C}$. Todo o procedimento de ozonização foi conduzido em uma capela de exaustão da marca Quimis modelo 216.11, visando minimizar os riscos de aspiração do gás ozônio, seguindo as normas internacionais de segurança.

Após a ozonização, os óleos foram avaliados quanto a sua esterilidade. Foram então retirados $0,1 \mathrm{~mL}$ de cada óleo e inoculados em placas de Petri contendo meio ágar triptecaseina soja (TSA, Oxoid ${ }^{\circledR}$ ), incubados a $37^{\circ} \mathrm{C}$ por $24 / 48$ horas, quando foi verificada a ausência de crescimento microbiano. Foi considerado estéril 
o óleo que não apresentou nenhuma colônia no meio de cultura.

Os óleos essenciais ozonizados foram armazenados em frascos âmbar, identificados e mantidos sob refrigeração a 8 ำ.

\section{Preparação do inóculo}

Para o procedimento de preparação do inóculo, primeiramente, S. schenckii foi cultivado em meio CSD submetido a agitação orbital constante $(225 \mathrm{rpm})$ e temperatura controlada $\left(28^{\circ} \mathrm{C}\right)$ por 5 dias. Foram preparadas suspensões do microrganismo em tubos solução salina estéril ( $\mathrm{NaCl} 0,5 \%)$, os quais foram padronizados segundo solução padrão do tubo 0,5 da escala McFarland, que corresponde a um inóculo de aproximadamente $10^{6}$ unidades formadoras de colônias $\mathrm{mL}^{-1}$ (UFC $\mathrm{mL}^{-1}$ ).

\section{Determinação da concentração inibitória mínima (CIM) e concentração fungicida mínima (CFM)}

Todas as avaliações foram realizadas em caldo CSD suplementado com detergente Tween 20 (concentração final de $0,5 \%(v / v)$. A linhagem de $S$. schenkii foi suspensa em caldo CSD para dar uma densidade final de $10^{6} \mathrm{CFU} \mathrm{mL} \mathrm{mL}^{-1}$, e estas foram confirmadas por contagens de células viáveis.

Os experimentos foram conduzidos empregando-se concentrações que variaram de 0,00 a $100 \%$, sendo elas: $0,39 \%, 0,78 \%, 1,56 \%, 3,12 \%, 6,25 \%, 12,50 \%, 25 \%, 50 \% 100 \%$ e os controles negativo e positivo.

A concentração inibitória mínima (CIM) e a concentração fungicida mínima (CFM) foram avaliadas de acordo o procedimento recomendado pela CLSI $(2008 ; 2012)$. A CIM foi determinada por um método de microdiluição em placas de 96 poços. Após incubação a 37ํㅡ por 24h, a CIM foi avaliada, sendo que presença de células bacterianas viáveis nas concentrações não inibitórias foi determinada pela adição, em cada amostra, do corante 2,3,5 -Triphenyltetrazolium Chloride, no volume de $50 \mu \mathrm{L}$. Isto tornou possível distinguir as amostras vivas, coloridas de vermelho, daquelas mortas que mantiveram a sua cor. A concentração inibitória mínima foi considerada como a menor concentração de óleo essencial capaz de inibir o desenvolvimento bacteriano (SYLVESTER, 2011).

Para determinar a CFM, $20 \mu \mathrm{l}$ de amostras de todos os poços com inibição total do crescimento e do último poço com crescimento foram inoculados na superfície de placas de Petri com ágar Sabouraud Dextrose. As placas foram incubadas a $28^{\circ} \mathrm{C}$ por 3 dias ou até que o crescimento do fungo fosse observado nas amostras controle. Os valores de CFM foram determinados como a concentração mais baixa de óleos essenciais, sem crescimento visível (AIEMSAARD et al., 2017).

\section{Cinética fungicida dos óleos essenciais}

Foi empregada a metodologia descrita por Allahghadri et al. (2010). Foram adicionados em tubos, 40 $\mu \mathrm{l}$ de cada óleo essencial na diluição determinada por CFM a cada $5 \mathrm{~mL}$ de caldo de CSD contendo suspensão

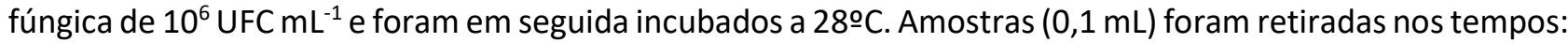
$0^{\prime}, 5^{\prime}, 10^{\prime}, 20^{\prime}, 60^{\prime}, 120^{\prime}, 240^{\prime}, 480^{\prime}$ e 24horas. As amostras foram espalhadas em cultura em agar Sabouraud Dextrose, incubadas durante $24 / 48 \mathrm{~h}$ a 28 으. Todas as avaliações foram realizadas em triplicata. 
As colónias microbianas foram contadas após o período de incubação. Foi realizada uma avaliação sobre a variação da carga microbiana a fim de observar qual óleo essencial apresentou a maior variação negativa (queda) na contagem microbiana.

Essa análise mostrou que quanto maior a variação negativa, maior foi a eficácia do óleo essencial. Nesse contexto, a variação percentual da contagem microbiana consistiu da seguinte relação:

$$
\text { Contagem microbiana } \text { óleo essencial }(\%)=\frac{\left(\text { Contagem }_{0,39 \%}-\text { Contagem }_{0,0} \%\right)}{\text { Contagem }_{0,0} \%} \times 100
$$

Essa relação foi empregada para todos os óleos essenciais avaliados e para todas as concentrações empregadas. De acordo com a expressão acima, variações negativas mostram diminuição na contagem microbiana e variações positivas mostram aumento da contagem microbiana à medida que a concentração do respectivo óleo essencial aumenta.

\section{Análise estatística}

Os dados foram avaliados através de análise descritiva da variação da contagem microbiana, conforme os tempos de exposição aos diferentes óleos essenciais. A Abordagem dos dados de contagem microbiana, foi realizada, por meio de gráficos de linha, a fim de observar a evolução da variação da contagem microbiana com o tempo.

O Teste de Mann-Whitney foi utilizado para a comparação da variação da contagem microbiana em relação ao tratamento com ozônio. Foi empregado o Teste de Kruskal-Wallis para a comparação da variação da contagem microbiana em relação aos óleos essenciais e ao tratamento de ozonização. Todos os testes estatísticos foram aplicados com nível de significância de $5 \%(P<0,05)$. Os softwares utilizados foram Minitab 18 (Minitab Inc.) e MedCalc 14.8.1 (MedCalc Software Inc.).

\section{RESULTADOS E DISCUSSÃO}

Em um primeiro momento foi realizado um estudo com todos os óleos essenciais com o objetivo de avaliar a CFM, a fim de caracterizar o potencial de cada um dos óleos avaliados. Na Tabela 1, estão apresentados os resultados da CIM e da CFM para cada um dos óleos essenciais avaliados.

Os resultados da CIM e da CFM, na grande maioria dos casos, mostraram que o efeito do ozônio é significativo, já que a sua utilização diminui a quantidade dos óleos essenciais estudados. Neste contexto, o uso do ozônio otimiza o efeito sobre Sporothrix schenckii, auxiliando no controle da contaminação e, por conseguinte, diminuindo o tempo de sobrevivência do fungo.

Sharma et al. (2016), avaliaram os efeitos antifúngicos sobre Fusarium oxysporum $f$. sp. lycopersici 1322 de quatro óleos essenciais: cravo (Syzygium aromaticum), capim-limão (Cymbopogon citratus), menta (Mentha piperita) e eucalipto (Eucalyptus globulus) e, verificaram que o efeito inibitório dos óleos evidenciou atividade dependente da dose no fungo testado. O mais ativo foi o óleo de cravo, exibindo inibição completa do crescimento micelial e germinação de esporos a 125 ppm. Os óleos essenciais de capim-limão, menta, eucalipto foram inibitórios em concentrações mais altas 
Na presente pesquisa, o óleo de cravo foi o mais eficaz, tanto in natura como ozonizado, seguido pelos óleos de citronela e eucalipto globolus (Tabela 1).

O cravo contém compostos bioativos que podem ser potencialmente usados para fins medicinais. $O$ eugenol é o principal componente do óleo essencial de cravo e é o principal responsável pela atividade antimicrobiana (PAVESI et al., 2018).

A variação percentual da contagem microbiana foi determinada por meio de estatística descritiva (Tabela 2), a fim de observar o potencial antifúngico dos óleos essenciais in natura e dos óleos essenciais ozonizados.

Tabela 1: Concentração inibitória mínima (CIM) e concentração fungicida mínima (CFM) para os óleos essenciais in natura e ozonizados frente a Sporothrix schenckii.

\begin{tabular}{lllll}
\hline Óleo essencial & CIM (\%) & & CFM (\%) & \\
\cline { 2 - 5 } & Com ozônio & Sem ozônio & Com ozônio & Sem ozônio \\
\hline Canela & 3,1 & 12,5 & 1,5 & 12,5 \\
Cravo & 0,8 & 1,5 & 0,4 & 0,4 \\
Citronela & 0,8 & 0,8 & 0,8 & 0,8 \\
Menta & 3,1 & 25 & 6,2 & 50 \\
Eucalipto G. & 0,8 & 6,25 & 0,4 & 1,5 \\
Eucalipto S. & 3,4 & 3,1 & 0,4 & 6,25 \\
\hline
\end{tabular}

Tabela 2: Estatística descritiva da variação percentual (\%) global da contagem microbiana em relação aos óleos avaliados.

\begin{tabular}{llllllll}
\hline \multirow{2}{*}{ Óleo essencial } & \multicolumn{3}{c}{ Com ozônio } & \multicolumn{5}{c}{ Sem ozônio } & \multirow{2}{*}{ Valor P1 } \\
\cline { 2 - 6 } & $\mathrm{n}$ & Média $\pm D \mathrm{DP}^{2}$ & Mediana & $\mathrm{n}$ & Média $\pm \mathrm{DP}$ & Mediana & 0,081 \\
Citronela & 3 & $-99,9 \pm 0,0$ & $-99,9$ & 3 & $-99,9 \pm 0,0$ & $-99,9$ & 0,173 \\
Canela & 6 & $-67,0 \pm 36,1$ & $-67,8$ & 6 & $-55,8 \pm 48,5$ & $-59,0$ & $\mathbf{0 , 0 0 7}$ \\
Cravo & 3 & $-99,9 \pm 0,00$ & $-99,9$ & 18 & $-45,5 \pm 30,9$ & $-46,4$ & $\mathbf{0 , 0 2 8}$ \\
Eucalipto G & 3 & $-99,9 \pm 0,00$ & $-99,9$ & 6 & $-99,0 \pm 0,7$ & $-99,1$ & 0,678 \\
Eucalipto S & 12 & $-37,3 \pm 43,1$ & $-22,7$ & 15 & $-21,8 \pm 40,4$ & 0,00 & 0,591 \\
Menta & 12 & $-66,1 \pm 32,2$ & $-71,2$ & 15 & $-66,2 \pm 30,1$ & $-80,0$ & 0 \\
\hline
\end{tabular}

${ }^{1}$ Valor P referente ao teste de Mann-Whitney a P<0,05. ${ }^{2} \mathrm{DP}$ : desvio padrão.

A estatística descritiva da variação global microbiana do Spothrix schenkii ao longo dos períodos, e as discrepâncias observadas nos ' $n$ ' indicam que alguns óleos essenciais anularam a carga microbiana em tempos reduzidos e outros em tempos avançados. Neste contexto, quanto menor o valor de $\mathrm{n}$, maior a eficácia à ação antifúngica do óleo essencial; em contrapartida, quanto maior o n, menor a eficácia da ação antifúngica do óleo.

Os resultados indicam diferenças significativas da variação microbiana global em dois óleos essenciais: cravo $(p=0,007)$ e eucalipto g. $(p=0,028)$, mostrando que o tratamento com ozônio surtiu efeito positivo e significativo na diminuição da carga microbiana em ambos os casos.

Nos demais óleos avaliados, o ozônio apresentou efeito positivo na redução da carga microbiana, porém este efeito não foi significativo $(p>0,05)$.

As Figuras 1 e 2 mostram o comportamento das variações percentuais da contagem microbiana dos óleos essenciais de cravo e eucalipto globulus. A disposição dos intervalos de confiança para as variações da carga microbiana reitera a presença de diferenças significativas. Além disso, a não sobreposição dos intervalos de confiança também é um fator considerado na análise que confirma a existência de diferenças 
significativas na contagem microbiana em relação ao tratamento com ozônio.

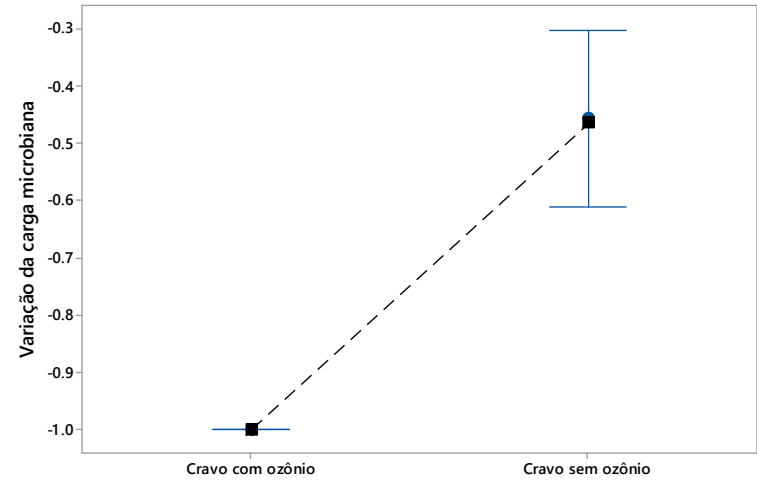

Figura 1: Variação percentual da contagem do óleo essencial de cravo. Nota: Pontos azuis referem-se à média e pontos pretos à mediana.

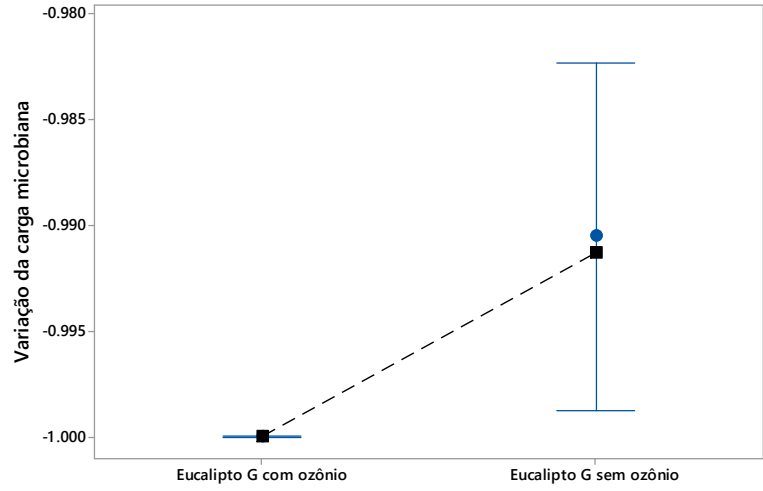

Figura 2: Variação percentual da contagem microbiana do óleo essencial de eucalipto g. Nota: Pontos azuis referem-se à média e pontos pretos à mediana.

O provável efeito sinérgico apresentado pelo uso do ozônio nos óleos de cravo, citronela e eucalipto globolus (Tabelas 1 e 2) evidenciam atividade antifúngica notável frente Sporotrix schenckii. O tratamento realizado com os óleos vegetais ozonizados leva à criação de um reservatório do composto, que é liberado lentamente na pele, graças ao fato de que ozônio pode ser considerado um ozonídeo de ácidos graxos insaturados (UGAZIO et al., 2020).

Pesquisas apontam que eventualmente os sistemas sinérgicos biomiméticos podem fornecer novas soluções para combater os patógenos de humanos e de animais (GERSHENZON et al., 2007). Os compostos orgânicos voláteis das plantas servem como respostas químicas à pressão de predadores e patógenos e em interações coespecíficas e mutualísticas. Atuam por meio de diversos modos de ação ligados à diversidade estrutural e funcional de seus componentes (RICHARDS et al., 2016). Devido a essas características, misturas multifacetadas e versáteis podem encontrar inúmeras aplicações. Individulamente ou em combinação com drogas clínicas, as misturas podem exibir atividades notáveis contra vários microrganismos patogênicos e efeitos sinérgicos entre seus constituintes também foram demonstrados (LOPES et al., 2017).

Na Figura 3 são apresentados o comportamento da variação da carga microbiana de Sporothrix em relação aos óleos essenciais e o uso do ozônio. Os resultados evidenciaram que os óleos de citronela, canela e eucalipto g. presentaram maior eficácia no combate ao fungo, visto que a carga microbiana se tornou nula em um curto tempo de exposição. No caso do óleo de cravo, o tempo de exposição da amostra ao ozônio surtiu efeito significativo na diminuição da carga microbiana, apresentando efeito sinérgico ao óleo essencial.

De uma forma geral, os óleos de citronela, canela e eucalipto globolus apresentaram-se como mais eficazes na diminuição da contaminação por Sporothrix schenckii, independentemente do tratamento com ozônio, pois nestes casos, a carga microbiana foi anulada em tempos curtos (até 20 minutos).

Os óleos essenciais são misturas complexas de origem vegetal cujos constituintes diferem com base em suas origens. Várias atividades biológicas foram relatadas, incluindo atividades antimicrobiana, antiinflamatória, antimutagênica, antidiabética e anticâncer (RAUT et al., 2014) antifúngicas de óleos essenciais de várias espécies de plantas, entre elas Cinnamomum spp. (MAHBOUDI et al., 2015), Mentha 
piperita (TULLIO et al., 2019), Syzygium aromaticum (BATIHA et al., 2020), e atividade antibacteriana frente bactérias Gram-positivas e Gram-negativas (HASHIM et al., 2017). Além disso, os óleos essenciais são capazes de produzir efeito sinérgico quando combinados com antifúngicos sintéticos e outras molêculas (AMBER et al., 2010; MITTAL et al., 2019).
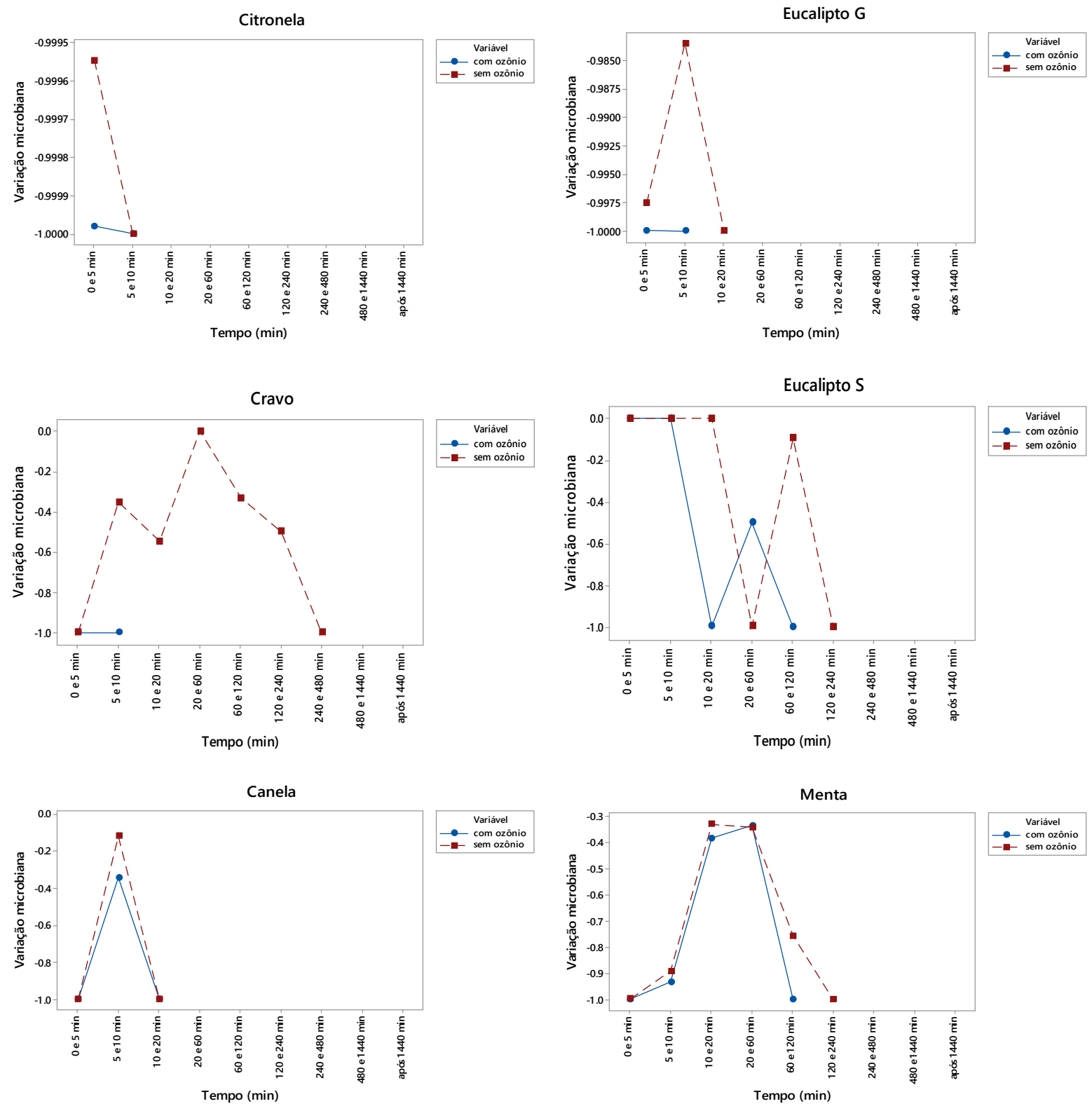

Figura 3: Variação percentual média da contagem microbiana dos óleos essenciais in natura e ozonizados de Citronela (Cymbopogon winterianus), canela Cinnamomum cassia); cravo (Syzygium aromaticum), eucalipto G. (Eucalyptus globolus), eucalipto S (Eucalyptus staigeriana) e menta (Mentha piperita).

O óleo de cravo em combinação com ozônio (óleo ozonizado) apresentou maior efetividade, agindo de forma pontual e auxiliando na redução da carga microbiana em 20 minutos, evidenciando a eficácia do controle de S. schenckii. Os óleos de eucalipto s. e menta foram os menos eficazes, anulando a carga microbiana em até 240 minutos. Devido a promissora atividade antimicrobiana os óleos essenciais foram usados em combinação com outras molêculas com a finalidade de reduzir a toxicidade da droga, efeitos colaterais e resistência a agentes únicos (TULLIO et al., 2019).

A quimiorresistência de patógenos tem se tornado um fenômeno mundial preocupante e a 
mortalidade global de pacientes que sofrem de infecções microbianas está aumentando regularmente. A resistência a azóis e resistências cruzadas, são relevantes, o que dificulta a terapia antifúngica (WOODHOUSE et al., 2014; SHOR et al., 2015).

O tratamento de micoses com agentes químicos antifúngicos sistêmicos, como cetoconazol, fluonazol e derivados de itraconazol, apresentam efeitos colaterais, em particular, quando esses produtos químicos são usados por longo prazo. Portanto, a busca por alternativas adequadas para essas drogas é continua (MITTAL et al., 2019). Uma abordagem possível é usar a terapia com ozônio no tratamento de fungos patogênicos (ZANARDI et al., 2008; ALMEIDA et al., 2012; UGAZIO et al., 2020). Na presente pesquisa, os óleos de cravo, citronella e eucalipto (E. globolus) apresentaram eficácia no controle in vitro de Sporothrix schenckii, apontando assim, a possibilidade de utilização como um método alternativo na terapéutica antifúngica.

\section{CONCLUSÕES}

Os óleos essenciais 'in natura' e ozonizados de canela, cravo, citronela, eucalipto (Eucalyptus globolus e E. staigeriana) e menta apresentaram atividade antifúngica frente a Sporothrix schenckii. O óleo de cravo ozonizado foi o mais eficaz na redução da carga fúngica, sendo necessários 20 minutos para eliminar totalmente as estruturas fúngicas. A eficácia do óleo de cravo ozonizado evidencia a possibilidade do uso na terapêutica antifúngica de $S$. schenckii.

\section{REFERÊNCIAS}

AIEMSAARD, J.; PUNAREEWATTANA, K.. Antifungal activities of essential oils of Syzygium aromaticum, Piper betle, and Ocimum sanctum against clinical isolates of canine Dermatophytes. Science Asia, v.43, n.5, p.223-228, 2017. DOI: https://doi.org.10.2306/scienceasia1513$\underline{1874.2017 .43 .223}$

ALLAHGHADRI, T.; RASOOLI, I.; OWLIA, P.; NADOOSHAN, M. J.; GHAZANFARI, T.; TAGHIZADEH, M.; ASTANEH, S. D.. Antimicrobial property, antioxidant capacity and cytotoxicity of essential eil from cumi.; produced in Iran. Journal of Food Science, v.75, n.2, p.H54-H61, 2010.

ALMEIDA, N. R.; BEATRIZ, A.; MICHELETTI, A. C.; ARRUDA, E. J.. Ozonized vegetable oils and therapeutic properties: A review. Electronic Journal of Chemical, v.4, p.313-326, 2012.

AMBER, K.; AIJAZ, A.; IMMACULATA, X.; LUQMAN, K. A.; NIKHAT, M.. Anticandidal effect of Ocimum sanctum essential oil and its synergy with fluconazole and ketoconazole. Phytomedicine, v.17, p.921-925, 2010. DOI: https://doi.org.10.1016/i.phymed.2010.02.012

BARROS, M. B.; PAES, R. A.; SCHUBACH, A. O.. Sporothrix schenckii and Sporotrichosis. Clinical Microbiology Reviews, v.24, n.4, p.633-654, 2011. DOI:

https://doi.org.10.1128/CMR.00007-11

BATIHA, G. E. S.; ALKAZMI, L. M.; WASEF, L. G.; BESHBISHY, A. M.; NADWA, E. H.; RASHWAN, E. K.. Syzygium aromaticum L. (Myrtaceae): Traditional Uses, Bioactive Chemical
Constituents, Pharmacological and Toxicological Activities. Biomolecules, v.10, n.202, p.1-16, 2020. DOI: https://doi.org.10.3390/biom10020202

BONIFAZ, A.; TIRADO-SÁNCHEZ, A.. Cutaneous disseminated and extracutaneous sporotrichosis: current status of a complex disease. Journal of Fungi, v.3, n.6, p.1-13, 2017. DOI: https://doi.org.10.3390/jof3010006

CLSI. Clinical and Laboratory Standards Institute. Reference Method for Broth Dilution Antifungal Susceptibility Testing of Filamentous Fungi; Approved Standard CLSI Document M38-A2. Wayne: CLSI, 2008.

CLSI. Clinical and Laboratory Standards Institute. Reference Method for Broth Dilution Antifungal Susceptibility Testing of Yeasts; Fourth Informational Supplement; Document M27-S4. Wayne: CLSI, 2012.

GERSHENZON, J.; DUDAREVA, N.. The function of terpene natural products in the natural world. Nature Chemical Biology, v.3, p.408-414, 2007. DOI: https://doi.org/10.1038/nchembio.2007.5

HASHIM, G. M.; ALMASAUDI, S. B.; AZHAR, E.; AL JAOUNI, S. K.; HARAKEH, S.. Biological activity of Cymbopogon schoenanthus essential oil. Saudi Journal of Biological Sciences, v.24, n.7, p.1458-1464, 2017.

KUMAR, V.; MATHELA, C. S.; TEWARI, A. K.; BISHT, K. S.. In vitro inhibition activity of essential oils from some 
Lamiaceae species against phytopathogenic fungi. Pesticide Biochemical and Physiology Journal, v.114, 67e71, 2014 https://doi.org/10.1016/i.pestbp.2014.07.001

LOPES, G.; PINTO, E.; SALGUEIRO, L.. Natural products: an alternative to conventional therapy for dermatophytosis? Mycopathologia, v.182, p.143-167, 2017.Doi: https://doi.org/10.1007/s11046-016-0081-9

MAHBOUDI, M.; KAZEMPOUR, N.. The antifungal activity of Artemisia sieberi essential oil from different localities of Iran against dermatophyte fungi. Journal of Medical Mycology, v.25, p.e65-71, 2015. DOI:

https://doi.org.10.1016/j.mycmed.2015.02.042

MITTAL, R. P.; RANA, A.; JAITAK, V.. Essential oils: an impending substitute of synthetic antimicrobial agents to overcome antimicrobial resistance. Current Drug Targets, v.20, n.6, p.605-624, 2019.

PAVESI, C.; BANKS, L. A.; HUDAIB, T.. Antifungal and antibacterial activities of eugenol and non-polar extract of Syzygium aromaticum L. Journal of Pharmaceutical Sciences and Research, v.10, n.2, p.337-339, 2018.

RAUT, J. S.; KARUPPAYIL, S. M.. A status review on the medicinal properties of essential oils. Industrial Crops and Products, v.62, p.250-64, 2014. DOI: https://doi.org/10.1016/i.indcrop.2014.05.055

RICHARDS, L. A.; GLASSMIRE, A. E.; OCHSENRIDER, K. M.; SMILANICH, M. A.; DODSON, C. D.; JEFFREY, C. S.; DYER, L. A.. Phytochemical diversity and synergistic effects on herbivores. Phytochemistry Reviews, v.15, p, 1153-1166, 2016. DOI: https://doi.org/10.1007/s11101-016-9479-8

RODRIGUES, A. M.; HOOG, S.; CAMARGO, Z. P.. Emergence of pathogenicity in the Sporothrix schenckii complex. Medical Mycology, v.51, n.4, p.405-412, 2013.

SHARMA, A.; RAJENDRAN, S.; SRIVASTAVA, A.; SHARMA, S.; KUNDU, B.. Antifungal activities of selected essential oils against Fusarium oxysporum f. sp.Lycopersici 1322, with emphasis on Syzygium aromaticum essential oil. Journal of Bioscience and Bioengineering, v.20, p.1-6, 2016. DOI: http://dx.doi.org/10.1016/j.jbiosc.2016.09.011

SHOR, E.; PERLIN, D. S.. Coping with stress and the emergence of multidrug resistance in fungi. PLoS Pathology, v.11, n.e1004668, 2015. DOI: https://doi.org/10.1371/journal.ppat.1004668

SIDDIQUI, S. A.; ISLAM, R.; ISLAM, R.; JAMAL, A. H. M.; PARVIN, T.; RAHMAN, A.. Chemical composition and antifungal properties of the essential oil and various extracts of Mikania scandens (L.) Willd, Arab. Journal of Chemistry, v.10, n.2, 2017. DOI: https://doi.org/10.1016/i.arabjc.2013.07.050

SIHAM, Y.; HAJAR, B.; MILOUD, E. K.; BRAHIM, M.; HOUSAINE, T.; MUSTAPHA, B.. Determination of chemical composition and evaluation of antioxidant and antimicrobial activities of Clove oil obtained from Syzygium aromaticum Moroccan species. International

Journal of Research in Pharmaceutical Sciences, v.11, n.2, p.2568-2574, 2020. DOI:

https://doi.org/10.26452/ijrps.v11i2.2261

SONG, Y.; LI, S. S.; ZHONG, S. X.; LIU, Y. Y.; YAO, L.; HUO, S. S. Report of 457 sporotrichosis cases from Jilin province, northeast China, a serious endemic region. Journal of the European Academy of Dermatology and Venereology, v.27, n.3, p.313-318, 2013. DOI: https://doi.org.10.1111/j.1468-3083.2011.04389.x

SYLVESTER, P. W.. Optimization of the tetrazolium dye (MTT) colorimetric assay for cellular growth and viability. Methods in Molecular Biology, v.716, p.157-168, 2011.

TÉLLEZ, M. D.; BATISTA-DUHARTE, A.; PORTUONDO, D.; QUINELLO, C.; BONNE-HERNÁNDEZ, R.; CARLOS, I. Z.. Sporothrix schenckii complex biology: environment and fungal pathogenicity. Microbiology, v.160, n.11, p.23522365, 2014. DOI: https://doi.org.10.1099/mic.0.081794-0

TULLIO, V.; ROANA, J.; SCALAS, D.; MANDRAS, N.. Evaluation of the Antifungal Activity of Mentha $x$ piperita (Lamiaceae) of Pancalieri (Turin, Italy) Essential Oil and Its Synergistic Interaction with Azoles. Molecules, v.24, n.3148, 2019. DOI: https://doi.org.10.3390/molecules24173148

UGAZIO, E.; TULLIO, V.; BINELL, A.; TAGLIAPIETRA, S.; DOSIO, F.. Ozonated oils as antimicrobial systems in topical applications. Their characterization, current applications, and advances in improved delivery techniques. Molecules, v.25, n.334, 2020. DOI: https://doi.org.10.3390/molecules25020334

ZANARDI, I.; BORRELLI, E.; VALACCHI, G.; TRAVAGLI, V.; BOCCI, V.. Ozone: A Multifaceted Molecule with Unexpected Therapeutic Activity. Current Medicinal Chemistry, v.23, n.4, p.304-314, 2016.

ZANARDI, I.; TRAVAGLI, V.; GABBRIELLI, A.; CHIASSERINI, L.; BOCCl, V.. Physico-chemical characterization of sesame oil derivatives. Lipids, v.43, p.877-886, 2008.

WOODHOUSE, M.; FARRAR, J.. Policy: an intergovernmental panel on antimicrobial resistance. Nature, v.509, p.555-557, 2014. DOI: https://doi.org/10.1038/509555a

A CBPC - Companhia Brasileira de Produção Científica (CNPJ: 11.221.422/0001-03) detém os direitos materiais desta publicação. Os direitos referem-se à publicação do trabalho em qualquer parte do mundo, incluindo os direitos às renovações, expansões e disseminacões da contribuicão, bem como outros direitos subsidiários. Todos os trabalhos publicados eletronicamente poderão posteriormente ser publicados em coletâneas impressas sob coordenação da Sustenere Publishing da Companhia Brasileira de Produção Científica e seus parceiros autorizados. Os (as) autores (as) preservam os direitos autorais, mas não têm permissão para a publicação da contribuição em outro meio, impresso ou digital, em português ou em tradução. 